\section{Evaluation of Biopolymer-coated Fiber Containers for Container-grown Plants}

\author{
Kenneth G. McCabe ${ }^{1}$, James A. Schrader ${ }^{1,5}$, Samy Madbouly ${ }^{2,4}$, \\ David Grewell ${ }^{3}$, and William R. Graves ${ }^{1}$
}

ADDITIONAL INDEX WORDS. biocontainer, biodegradable, biorenewable, coir, greenhouse, peat, sustainability, water-use efficiency

SUMMARY. Biocontainers made of coconut coir, paper, peat, wood, or other natural fibers are considered sustainable alternatives to containers made of petroleum-based plastics, but growers' acceptance and use of fiber containers have been limited by their comparatively high cost, low strength and durability, and poor water-use efficiency (WUE). We hypothesized that coating fiber containers with biopolymers would improve their strength, durability, and WUE during plant production. We compared the effectiveness of fiber containers of coir, paper, and wood that were either uncoated or coated with one of four biopolymers [polyamide (PA), polylactic acid (PLA), polyurethane (PU), or tung oil (TO)], peat-fiber containers that were uncoated, and injection-molded containers made of petroleum-based plastic. Ease of coating was assessed, along with the cost and strength of containers, their effectiveness during greenhouse production of 'Honeycomb' marigold (Tagetes patula), 'Autumn Bell' pepper (Capisicum annumm), 'Madness Red' petunia (Petunia $\times$ bybrida), 'St. John's Fire' salvia (Salvia splendens), and 'Rutgers' tomato (Solanum lycopersicum), and their WUE during production of salvia and tomato. Castor oil-based PU was the least expensive biopolymer coating and was easy to apply as a water-based dispersion. The other biopolymers required a hazardous and costly organic solvent (e.g., chloroform). Coatings of PA, PLA, and PU increased container strength and durability, and improved WUE during plant production. Coated paper-fiber containers resisted horizontal compression better than petroleumplastic containers. Greenhouse-grown plants in containers coated with PA, PLA, or PU were larger and rated healthier and of better quality than plants grown in uncoated or TO-coated fiber containers. Plants grown in paper- and coir-fiber containers coated with PA, PLA, or PU were similar in health and size to plants grown in petroleum-plastic containers. Two coatings of PU on paper-fiber containers resulted in WUE similar to that of petroleum-plastic containers for both 4- to 5-inch and gallon sizes. Coating fiber containers with biopolymers slowed, but did not halt, their degradation in soil, indicating that decomposition in soil may be a suitable end-of-life option for biopolymer-coated fiber containers. Our results support the hypothesis that coating fiber containers with biopolymers can improve their effectiveness for crop production, while maintaining an improvement in sustainability over petroleum plastic. Paper-fiber containers coated with PU showed particular promise and were similar in material cost and performance to containers made of petroleum-based plastic.

$\mathrm{V}$ alued at $\$ 10.5$ billion in 2009 , the container crops industry is a large sector of commercial horticulture that produces over four

This research was supported in part by the USDA Specialty Crops Research Initiative (USDA-SCRI project number IOW05306) and by Iowa State University.

We thank Bryan Peterson and Peter Lawlor for their helpful critiques of the manuscript. We also thank Kellie Walters for her technical assistance during trial establishment and data collection.

${ }^{1}$ Department of Horticulture, Iowa State University, 106 Horticulture Hall, Ames, IA 50011

${ }^{2}$ Department of Materials Science and Engineering, Iowa State University, Ames, IA 5001

${ }^{3}$ Department of Agricultural and Biosystems Engineering, Iowa State University, Ames, IA 50011

${ }^{4}$ Department of Chemistry, Faculty of Science, Cairo University, Orman-Giza, Egypt

${ }^{5}$ Corresponding author. E-mail: jschrade@iastate.edu billion plants in containers per year and uses over 1.6 billion pounds of petroleum plastic for containers (Schrader, 2013; Schrader et al., 2013; U.S. Department of Agriculture,
2013). Most containers used for commercial crop production are used only once and discarded by either the grower or the consumer. Only $8.8 \%$ of the plastic waste generated in the United States is recycled (U.S. Environmental Protection Agency, 2013), and disposal of single-use containers contributes to plastic accumulation in landfills. The petroleum-plastic waste generated by current cropping practices, coupled with the low rate of recycling, has raised concerns about the sustainability of this type of system. Despite their negative environmental impact and rising costs that are tied to oil prices, petroleum plastics have remained popular because of their high strength, durability, and versatility. Plastics can be molded into virtually any shape and size and have remained relatively affordable and economically accessible (Evans and Hensley, 2004; Koeser et al., 2013a). Plastic containers are lightweight, compatible with mechanized plant production, and suitable for shipping (Helgeson et al., 2009). Plastic containers enable efficient production of plant material regardless of species and duration of the crop-production cycle, but producers and consumers are becoming less tolerant of their negative environmental impacts.

Fiber-based biocontainers have emerged as sustainable alternatives to petroleum-plastic containers, but growers' acceptance of them has been low because of their higher cost and limited availability when compared with petroleum-plastic containers, poor WUE during production, and poor structural integrity and durability (Evans and Karcher, 2004; Hall et al., 2009; Koeser et al., 2013b). Wholesale prices for 4- to 5-inch fiber-based containers range from about $\$ 0.02$ more than plastic containers for a paper-fiber container, to nearly double the price for

\begin{tabular}{llll}
\hline $\begin{array}{l}\text { Units } \\
\text { To convert U.S. to SI, } \\
\text { multiply by }\end{array}$ & U.S. unit & SI unit & $\begin{array}{l}\text { To convert SI to U.S., } \\
\text { multiply by }\end{array}$ \\
\hline 10 & $\%$ & $\mathrm{~g} \cdot \mathrm{L}^{-1}$ & 0.1 \\
29.5735 & $\mathrm{fl} \mathrm{oz}$ & $\mathrm{mL}$ & 0.0338 \\
3.7854 & gal & $\mathrm{L}$ & 0.2642 \\
2.54 & inch $(\mathrm{es})$ & $\mathrm{cm}$ & 0.3937 \\
25.4 & inch $(\mathrm{es})$ & $\mathrm{mm}$ & 0.0394 \\
16.3871 & inch & $\mathrm{cm}^{3}$ & 0.0610 \\
0.4536 & $\mathrm{lb}$ & $\mathrm{kg}$ & 2.2046 \\
28.3495 & $\mathrm{oz}$ & $\mathrm{g}$ & 0.0353 \\
1 & $\mathrm{ppm}$ & $\mathrm{mg} \cdot \mathrm{L}^{-1}$ & 1 \\
0.0069 & $\mathrm{psi}$ & $\mathrm{MPa}$ & 145.0377 \\
$\left({ }^{\circ} \mathrm{F}-32\right) \div 1.8$ & ${ }^{\circ} \mathrm{F}$ & ${ }^{\circ} \mathrm{C}$ & $\left({ }^{\circ} \mathrm{C} \times 1.8\right)+32$
\end{tabular}


a coir-fiber container. Even a $\$ 0.02$ increase in cost per container translates into large cost increases when growers purchase thousands of containers. Cost of fiber-based containers coupled with increased water use and poor durability (Dennis et al., 2010; Koeser et al., $2013 b)$ leads most growers to resist conversion to more sustainable production methods that are free from petroleumplastic containers.

Water availability is an important concern in container crop production due to urban expansion and increased competition for water use. Production costs associated with water usage are expected to increase in coming years, motivating producers to adopt technologies that help improve WUE (Beeson et al., 2004). Water usage during crop production in fiber containers has been studied, and Evans and Karcher (2004) reported that crop production in peat-fiber containers used 2.25 times the water needed for production in petroleumplastic containers. Koeser et al. (2013b) concluded that growing plants in containers made from porous materials (i.e., peat, manure, straw, and wood) used more water than growing comparable plants in containers made of impervious materials such as plastic, biopolymer, and solid rice hull. Therefore, modifications to reduce evaporation through porous sidewalls represent a potential improvement that could be made to fiber-based containers.

Fiber-based containers also exhibit insufficiencies in structural performance when compared with petroleum-plastic containers. Container strength and durability are important to growers because many aspects of plant production are mechanized. Adequate strength, impact resistance, and durability are needed for containers to function throughout mechanized container filling, transplanting, spacing, shipping, and handling. These mechanized operations require containers to be resilient and adaptable, but many fiber-based containers are unlikely to hold up sufficiently. Structural performance of some fiber containers may be adequate when containers are new and dry, but durability diminishes after saturation and during crop production. Evans and Karcher (2004) reported that the longitudinal pressure required to crush peat-fiber containers is $\approx 7.3$ times greater for dry containers than for wet containers, indicating that strength of the porous material decreases when it is saturated. Evans et al. (2010) found that many types of fiber containers (i.e., coconut coir, rice, straw, peat, and wood), whether wet or dry, have lower vertical, lateral, and punch strengths than petroleumplastic containers, although paperfiber and plastic containers are similar in measures of strength. Irrigation methods can also affect the integrity of fiber containers during production. Peat-, paper-, and wood-fiber containers that are irrigated by ebb and flood systems show lower punch strengths when compared with containers that have been hand watered or drip irrigated (Koeser et al., 2013a).

Although research suggests that none of the commercially available fiber containers match the performance and function of plastic containers in all respects, there has been no research examining the potential improvements in performance and function of fiber containers that may result from coating them with sustainable bio-based polymers. We hypothesized that coating fiber containers with biopolymers would reduce evaporation through the container wall, improve WUE, and improve structural durability and performance throughout production. The objectives of our research were to l) evaluate and compare the cost, coating processability, performance, and biodegradation of three commercially available fiber containers coated with one of four biopolymers, 2) assess and compare the cost and performance of the best overall container/coating combination with one and two coats of biopolymer, and 3 ) describe the suitability of biopolymer-coated fibercontainer technology, as well as adjustments to cultural practices that would help maximize the effectiveness. If improvements in strength, durability, and WUE can be accomplished at a reasonable cost, biopolymer-coated fiber containers could become effective, sustainable alternatives to petroleumplastic containers.

\section{Materials and methods}

Three types of commercially available fiber containers (Table 1) were coated with one of four biopolymers to determine the effects of coating on container performance during container crop production. Containers of two size classes were used in experiments. The smaller size class of containers was composed of commercially available containers with 4- to 5-inch top diameters, which were selected to match as closely as possible in size (Table 1). Containers in the larger of the two size classes were no. 1 trade gallon (Table 1 ). The four bio-based polymers used for coating were PU (CUR 99; Alberdingk Boley, Greensboro, NC) that is derived from castor bean (Ricinus

Table 1. Commercially available fiber and petroleum-plastic containers evaluated during greenhouse experiments and structural assessments to determine the effects of dip-coating fiber containers with biopolymers.

\begin{tabular}{|c|c|c|c|}
\hline Container type ${ }^{\mathrm{z}}$ & Product name ${ }^{\mathrm{z}}$ & Volume $(\mathrm{mL})^{\mathrm{z}}$ & Manufacturer \\
\hline Gallon plastic controly ${ }^{\mathrm{y}}$ & Polytainer C-700 & 2809 & Nursery Supplies, Chambersburg, PA \\
\hline Paper fiber ${ }^{x}$ & ITML 04.50 fiber grow geranium pot & 600 & Myers Industries \\
\hline Gallon paper fiber ${ }^{x}$ & ITML 06.00 fiber grow nursery pot & 2660 & Myers Industries \\
\hline Wood fiber ${ }^{x}$ & $10 \times 10 \mathrm{~cm}$ Fertilpot round & 440 & Fertil, Boulogne Billancourt, France \\
\hline
\end{tabular}

${ }^{2} 1 \mathrm{Inch}=2.54 \mathrm{~cm}, \mathrm{l} \mathrm{gal}=3.7854 \mathrm{~L}, \mathrm{l} \mathrm{cm}=0.3937$ inch, $1 \mathrm{~mL}=0.0338 \mathrm{fl} \mathrm{oz}$.

${ }^{\mathrm{B}}$ Both sizes of petroleum-plastic control containers were injection molded. The 4.5 -inch plastic container was made of polypropylene and the gallon plastic container was made of high-density polyethylene.

${ }^{x}$ Containers dip-coated with one of four biopolymers: polyamide, polylactic acid, polyurethane, or tung oil. 
communis) oil and is typically used for making wood finishes and coatings; PA (Uni-Rez ${ }^{\mathrm{TM}}$ 2930; Arizona Chemical, Jacksonville, FL) that is derived from tall oil of pine tree (Pinus sp.) and is typically used in inks; PLA (Ingeo $^{\text {TM }} 6251 \mathrm{D}$; NatureWorks, Minnetonka, MN) that is derived from dextrose and can be used as an alternative to petroleum-based plastics for thermoforming, coating, injectionmolding, blow-molding, and fiber applications; and TO (Welch, Holme \& Clarke Co., Newark, NJ) that is derived from the seed kernels of the tung tree (Aleurites fordii) and is used for making wood finishes and coatings.

\section{Coating types and procedures}

To coat containers with $\mathrm{PU}$, the containers were immersed in the waterbased PU dispersion, hung on racks, and then dried in an incubator (1920; VWR International, Radnor, PA) at $40{ }^{\circ} \mathrm{C}$ for $2 \mathrm{~h}$. The containers were then coated a second time following the same process. Experiments to evaluate the effects of one vs. two coats of PU on WUE were conducted with 4.5-inch and gallon paper-fiber containers.

To coat containers with PLA or PA, we dissolved PLA or PA in chloroform and immersed the fiber containers in the biopolymer/chloroform solution. The use of chloroform required work to be conducted in a fume hood while wearing a respirator. PLA was mixed with chloroform at $10 \%$ PLA by weight in a stainless steel blender and poured into a steel pan. For the PA coating, which was only applied to 4.5 -inch paper-fiber containers due to its high cost, the concentration of PA in the chloroform solution was $15 \%$ by weight. Fiber containers were immersed in the biopolymer/chloroform solution and hung on a rack inside a fume hood. After excess solution dripped off the containers, the rack and containers were dried in an incubator at $40{ }^{\circ} \mathrm{C}$ for $30 \mathrm{~min}$. After drying, the coating process was repeated using the same technique.

Coating fiber containers with TO required a catalyst (boron trifluoride diethyl etherate) to initiate formation of solid material from the liquid solution to form a thin layer of cross-linked TO on the surfaces of the containers. The catalyst was mixed with $\mathrm{TO}$ at $1.8 \%$ by weight in a glass beaker, and the resulting solution was mixed with chloroform at $10 \%$ by weight in a stainless steel pan. The coating, drying, and recoating processes were similar to those used to coat containers with PLA and PA.

\section{Evaluations of coating processes and costs}

Ease of COATING Rating. The ease/difficulty of the coating process was assessed and compared among the four coating types by ascribing a rating of 1 to 5 , with 1 being the most difficult to coat and 5 being the easiest to coat. Ratings were based on the comparative difficulty of the coating processes and the handling and labor requirements for each type of biopolymer.

Cost calculations. Cost estimates for the biopolymer-coated containers and petroleum-plastic containers were based on 2012 wholesale costs for each commercially available type of container and the cost of materials used to coat them when applicable. The amount of biopolymer applied to the various containers was calculated as the mean difference between 15 uncoated and coated containers. Cost estimates did not include labor involved in the coating processes.

\section{Container evaluations}

GREENHOUSE PRODUCTION TRIAL. 'Honeycomb' marigold, 'Autumn Bell' pepper, 'Madness Red' petunia, 'St. John's Fire' salvia, and 'Rutgers' tomato were grown in 4 - to 5 -inch diameter round containers under standard container-production conditions for 5 weeks. Seedlings were started in 288-celled plug trays (T.O. Plastics, Clearwater, MN), grown to about $5 \mathrm{~cm}$ in height, transplanted into trial containers holding soilless substrate (LC-1; Sun Gro Horticulture, Agawam, MA), and arranged $10 \mathrm{~cm}$ apart in a randomized complete block design ( $n=14$ for each container $\times$ species factorial treatment) on expanded metal benches in a glassglazed greenhouse. The plastic containers were green 4.5-inch standard containers (Myers Industries, Akron, $\mathrm{OH}$ ) made of petroleum-based polypropylene (top diameter $=11.4 \mathrm{~cm}$, height $=9.4 \mathrm{~cm}$, volume $\left.=655 \mathrm{~cm}^{3}\right)$ (Table 1). Experimental units (container + plant) were fertilized once per week with $\approx 200 \mathrm{~mL}$ of $16.6 \mathrm{~N}-$
$5 \mathrm{P}-16.3 \mathrm{~K}$ mixed to supply nitrogen at $150 \mathrm{mg} \cdot \mathrm{L}^{-1}$ (Peters Excel ${ }^{\circledR}$ Multi Purpose and Cal-Mag; Everris International, Geldermalsen, The Netherlands) to produce healthy plants in the petroleum-plastic control containers. Air temperature was maintained at $26 \pm 5{ }^{\circ} \mathrm{C}$, relative humidity ( $\mathrm{RH}$ ) ranged from $25 \%$ to $87 \%$ (mean = $59 \%)$, and the mean photosynthetically active radiation $(P A R)$ at $1200 \mathrm{HR}$ was $530 \mu \mathrm{mol} \cdot \mathrm{m}^{-2} \cdot \mathrm{s}^{-1}$. After 5 weeks of growth, the plant in each experimental container unit was rated for plant health (blind rating by two experienced horticulturists on a scale of $0=$ worst/dead to 5 = best) and measured for shoot height and shoot width in two perpendicular directions. Indicators of poor health that resulted in lower ratings included chlorosis, necrosis, and stunted growth. The height and width measurements were used to calculate the threedimensional shoot volume for each plant (height $\times$ width $\times$ width). Five randomly selected replications were harvested from each container $\times$ species factorial treatment, and plants were washed of medium and samples were prepared and dried for $9 \mathrm{~d}$ at $33 \pm 5{ }^{\circ} \mathrm{C}$ and mean $\mathrm{RH}$ of $26 \%$. Dried plants were held for $24 \mathrm{~h}$ in ambient conditions before recording root dry weight, shoot dry weight, and total plant dry weight (shoot + root dry weight) of each sample.

STRUCTURAL EVAlUations AND CONTAINER INTEgRITY. Structural evaluations were performed on 4- to 5 -inch uncoated- and coated-fiber containers and a petroleum-plastic container to determine whether biopolymer coatings improved container strength and durability. Containers coated with TO were not evaluated for strength and durability because of their poor performance during the initial greenhouse production trial and their relatively high cost. Structural measurements of container "wet strength" were performed on a Universal Testing Machine (Instron ${ }^{\circledR}$, Norwood, MA) using new containers that had been submerged in water for $16 \mathrm{~h}$. Containers were compressed both vertically ( $n=4$ for each container/coating) and horizontally ( $n=$ 4 for each container/coating), and tensile strength was measured by pulling apart sections of container sidewall $(1 \times 3$ inch $)$ until breakage occurred ( $n=8$ for each container/coating). 
Vertical compression measurements were achieved by placing containers upright between two flat plates and compressing for $50 \mathrm{~mm}$. Horizontal compression measurements were achieved by placing containers on their side between two flat plates and compressing for $50 \mathrm{~mm}$. Although structural measurements were not performed on gallon-size containers, we visually assessed aesthetics and integrity of gallon-size PU-coated paper-fiber containers after being used for 5 months of redosier dogwood (Cormus sericea) production in an outdoor setting.

Degradation in SOIL. We compared the rate of material degradation and the suitability of container materials for end-of-life degradation in soil for up to 1.5 years. Trials were conducted in a field plot at a horticulture research farm of Iowa State University near Gilbert, IA, where the soil was a Clarion loam, fine-loamy, mixed, superactive, mesic Typic Hapludoll. Samples for the degradation assessment were new, one-fourth-sized container pieces that were weighed, placed in a nondegradable mesh bag, and buried $10 \mathrm{~cm}$ below the soil surface in a randomized complete block design ( $n=3$ for each container material) on 17 May 2012. During the first season of the degradation trial (until 29 Nov. 2012), mean daily maximum air temperature, minimum air temperature, and $10-\mathrm{cm}$ soil temperature were $23.6,12.0$, and $18.8^{\circ} \mathrm{C}$, respectively. During the second season of the degradation trial (25 May to 25 Nov. 2013), mean daily maximum air temperature, minimum air temperature, and 10-cm soil temperature were $22.8,11.3$, and $19.2^{\circ} \mathrm{C}$, respectively. The field plot was irrigated uniformly once per week by overhead irrigation with $\approx 1$ inch of water during each growing season. Samples of container material pieces were collected from the soil after 6 months and 1.5 years, washed to remove any remaining field soil, dried for $9 \mathrm{~d}$ at $33 \pm 5^{\circ} \mathrm{C}$ and mean $\mathrm{RH}$ of $26 \%$, and held for $24 \mathrm{~h}$ in ambient conditions before weighing. Percentage degradation (weight loss) was calculated for container materials after 6 months or 1.5 years in soil. Degradation data were not included for 1 year in the soil, because minimal degradation occurred over the winter between growing seasons.
WATER-USE EFFICIENCY OF 4- TO 5-INCH CONTAINER TYPES. Seedlings of 'St. John's Fire' salvia were started in 288-celled plug trays (T.O. Plastics), grown to $\approx 5 \mathrm{~cm}$ in height, transplanted into trial containers holding soilless substrate (LB-2, Sun Gro Horticulture), and arranged $15 \mathrm{~cm}$ apart in a completely randomized design $(n=5$ for each container $x$ species factorial treatment) on expanded metal benches in a glassglazed greenhouse. Trial containers were coated- and uncoated-fiber containers with 4- to 5-inch top diameters and plastic containers that were green 4.5-inch standard containers made of petroleum-based polypropylene (Table 1). Air temperature was maintained at $24 \pm 3{ }^{\circ} \mathrm{C}$, $\mathrm{RH}$ ranged from $17 \%$ to $80 \%($ mean $=46 \%)$, and mean PAR at 1200 HR was 400 $\mu \mathrm{mol} \cdot \mathrm{m}^{-2} \cdot \mathrm{s}^{-1}$ during the trial. Experimental units were grown for 8 weeks and fertilized once per week with 200 $\mathrm{mL}$ of $16.6 \mathrm{~N}-5 \mathrm{P}-16.3 \mathrm{~K}$ mixed to supply nitrogen at $150 \mathrm{mg} \cdot \mathrm{L}^{-1}$ (Peters Excel $^{\circledR}$ Multi Purpose and Cal-Mag). Water was applied as needed (visually assessed) to each experimental unit and at an amount that ensured the substrate in the container was at container capacity with little to no leaching. A drain tray was placed under each container/plant unit to capture any leachate. Amounts of both the applied and leached solutions were recorded for each experimental unit, and total water use was calculated as the difference in volume between liquid applied and liquid leached. WUE was calculated by dividing final plant dry weight (grams) by the volume of water used to produce the plant. The plant in each experimental unit was also rated for health; measured for shoot height and shoot width; and harvested, prepared, and dried to determine dry weight by using the same methods described for the greenhouse production trial.

Cumulative CONTAINer SCORES. Container types evaluated in the trials with 4 - to 5 -inch container sizes received a cumulative container score based on 10 measures of container cost and performance: cost per container; ease of coating; degradation in soil; total wet strength; greenhouse scores for grower rating, plant health, plant size, and WUE; and landscape scores for plant health and plant shoot volume. Results for each parameter were standardized to a common scale of 0 to 10 , for a maximum cumulative container score of 100 . The results from a landscape trial (data not shown) were included in the cumulative score to evaluate transplant establishment. Results from the landscape trial were from plants of the five species that were produced in the greenhouse production trial and transplanted and grown in a garden plot for 8 weeks with containers removed, crushed, and installed beneath plant roots.

COMPARISON OF ONE VS. TWO COATINGS OF PU ON 4.5-INCH PAPER-FIBER CONTAINERS. Initial $\mathrm{eX}-$ periments indicated that performance of PU-coated paper-fiber containers was similar to that of petroleum-plastic containers and that they were the most cost competitive of the coatedfiber containers we tested. Therefore, we performed additional experiments to evaluate the effect of one vs. two PU coatings applied to 4.5 -inch and no. I trade gallon paper-fiber containers, and to determine the degree to which one or two coats of PU improved WUE over that of uncoated containers.

Seedlings of 'Rutgers' tomato were started in 288-celled plug trays, grown to about $5 \mathrm{~cm}$ in height, transplanted into trial containers holding $600 \mathrm{~cm}^{3}$ of soilless substrate (LC-1), and arranged $15 \mathrm{~cm}$ apart in a randomized complete block design $(n=5$ for each container $\times$ species factorial treatment) on expanded metal benches in a glass-glazed greenhouse. Trial containers were 4.5 -inch paperfiber containers (Myers Industries) that were either uncoated or coated with one or two coats of PU, and green 4.5 -inch standard containers made of petroleum-based polypropylene (Table 1). Air temperature was maintained at $22 \pm 6{ }^{\circ} \mathrm{C}$, $\mathrm{RH}$ ranged from $15 \%$ to $82 \%($ mean $=46 \%)$, and the mean PAR at $1200 \mathrm{HR}$ was 421 $\mu \mathrm{mol} \cdot \mathrm{m}^{-2} \cdot \mathrm{s}^{-1}$ during the trial. Experimental units were grown for 6 weeks, and were fertilized once per week with $200 \mathrm{~mL}$ of $16.6 \mathrm{~N}-5 \mathrm{P}-16.3 \mathrm{~K}$ mixed to supply nitrogen at 150 $\mathrm{mg} \cdot \mathrm{L}^{-1}$ (Peters Excel ${ }^{\circledR}$ Multi Purpose and Cal-Mag). Water was measured and applied as needed (visually assessed) to each experimental unit, amounts of applied and leached solutions were quantified, and WUE was calculated at the end of the trial by 
using the same method described for the first WUE experiment. The plant in each experimental unit was rated for health; measured for shoot height and shoot width; and harvested, prepared, and dried as described for the first greenhouse experiment.

COMPARISON OF ONE VS. TWO COATINGS OF PU ON GALLON PAPERFIBER CONTAINERS. Seedlings of 'Rutgers' tomato were started in $12-$ 04 cell packs (T.O. Plastics), grown to $\approx 10 \mathrm{~cm}$ in height, transplanted into trial containers holding $2660 \mathrm{~cm}^{3}$ of soilless substrate (LC-1), and arranged $20 \mathrm{~cm}$ apart in a randomized complete block design $(n=6$ for each container $\times$ species factorial treatment) on expanded metal benches in a glass-glazed greenhouse. Trial containers were no. 1 trade gallon paperfiber containers (Myers Industries) that were either uncoated or coated with one or two coats of PU, and black no. 1 trade gallon Polytainer C-700 containers (Nursery Supplies, Chambersburg, PA) made of petroleumbased high-density polyethylene (top diameter $=16.0 \mathrm{~cm}$, height $=17.5 \mathrm{~cm}$, volume $=2809 \mathrm{~cm}^{3}$ ). Air temperature was maintained at $22 \pm 6{ }^{\circ} \mathrm{C}$, $\mathrm{RH}$ ranged from $15 \%$ to $83 \%$ $($ mean $=53 \%)$, and the mean $P A R$ at $1200 \mathrm{HR}$ was $349 \mu \mathrm{mol} \cdot \mathrm{m}^{-2} \cdot \mathrm{s}^{-1}$ during the trial. Experimental units were grown for 7 weeks and were fertilized once per week with $400 \mathrm{~mL}$ of $16.6 \mathrm{~N}-5 \mathrm{P}-16.3 \mathrm{~K}$ mixed to supply nitrogen at $150 \mathrm{mg} \cdot \mathrm{L}^{-1}$ (Peters Ex$\mathrm{cel}^{\circledR}$ Multi Purpose and Cal-Mag). Water was measured and applied as needed (visually assessed) to each experimental unit, amounts of applied and leached solutions were quantified, and WUE was calculated at the end of the trial as described for the first WUE experiment. The plant in each experimental unit was rated for health; measured for shoot height and shoot widths; and harvested, prepared, and dried as described for the first greenhouse experiment.

\section{Statistical analysis}

Data for all experiments were analyzed for main effects, interactions, and means-separation by using SAS $/$ STAT $^{\circledR}$ (SAS Institute, Cary, NC) or JMP ${ }^{\circledR}$ statistical software (SAS Institute). Means-separation statistics were conducted using Fisher's least significant difference model $(P \leq$ $0.05)$. Before analysis of data across species, a normalization procedure was used for data from each species in the greenhouse production experiment to calculate normalized means for total dry weights (Pyle, 1999), which enabled pooling of species to compare effects of container treatments. Normalization of individual observations was accomplished by the following formula: (normalized value $)=\mathrm{a}+(\mathrm{X}-\mathrm{A})(\mathrm{b}-\mathrm{a}) /(\mathrm{B}-\mathrm{A})$, where $\mathrm{A}=$ minimum of speciesspecific dataset, $B=$ maximum of species-specific dataset, $\mathrm{a}=$ minimum of normalized dataset $(0), b=$ maximum of normalized dataset (100), and $\mathrm{X}=$ original observation. A similar procedure was used to standardize separate parameters to a common scale of 0 to 10 for calculations of cumulative container score.

\section{Results \\ Cost and ease of coating}

Coating with PU was the easiest and least expensive of the four biopolymer coatings evaluated (Table 2 ). The PU was purchased as a waterbased dispersion in liquid form, which made overall processing easier and less hazardous than the other three biopolymer coating materials. Cost per container increased by $\$ 0.03$ for each PU-coated container compared with the cost of uncoated containers ( $\mathrm{Ta}$ ble 2). Coatings of PA and PLA were more difficult to apply than PU, but easier to apply than TO (Table 2). The use of chloroform as the organic solvent for PA, PLA, and TO made the coating process more difficult and hazardous when compared with coating with $\mathrm{PU}$ and required that the coating process be performed in a fume hood. Cost of coating with PA and PLA was 21 and 13 times the cost of coating with PU, respectively (Table 2). Cost per container increased $\$ 0.63$ for PA coating and $\$ 0.40$ for PLA coating for each container type (Table 2). TO was the most expensive and difficult biopolymer used for coating in our trials (Table 2). The requirement for a catalyst added another step to the process, increased costs, and created a critical period of 15 to $20 \mathrm{~min}$ during which containers needed to be coated before the TO solution solidified. Cost per container increased $\$ 1.53$ for each fibercontainer type when coated with TO (Table 2). The TO coating also adhered poorly to all of the fiber containers, especially coir fiber, and oily residue persisted on the container surface following the coating process.

Table 2. Cost per container and ease of coating for the various fiber containers dip-coated with biopolymers and petroleum-plastic containers.

\begin{tabular}{|c|c|c|}
\hline Container type ${ }^{z}$ & $\begin{array}{c}\text { Cost of } \\
\text { container }(\$)^{y}\end{array}$ & $\begin{array}{c}\text { Ease of coating } \\
(0-5 \text { scale })^{x}\end{array}$ \\
\hline 4.5-inch petroleum-based control & 0.12 & $\mathrm{NA}^{\mathrm{w}}$ \\
\hline Paper fiber & 0.14 & NA \\
\hline Paper fiber-PU coat & 0.17 & 5.0 \\
\hline Jiffy pot & 0.18 & NA \\
\hline Wood fiber & 0.20 & NA \\
\hline Coir fiber & 0.23 & NA \\
\hline Wood fiber-PU coat & 0.23 & 4.5 \\
\hline Coir fiber-PU coat & 0.26 & 4.5 \\
\hline Gallon paper fiber & 0.37 & NA \\
\hline Gallon paper fiber-PU coat & 0.47 & 5.0 \\
\hline Gallon petroleum-based control & 0.51 & NA \\
\hline Paper fiber-PLA coat & 0.54 & 2.5 \\
\hline Wood fiber-PLA coat & 0.60 & 2.5 \\
\hline Coir fiber-PLA coat & 0.63 & 2.0 \\
\hline Paper fiber-PA coat & 0.77 & 3.0 \\
\hline Paper fiber-TO coat & 1.67 & 1.0 \\
\hline Wood fiber-TO coat & 1.73 & 1.5 \\
\hline Coir fiber-TO coat & 1.76 & 0.5 \\
\hline
\end{tabular}

${ }^{\mathrm{z}} \mathrm{l}$ Inch $=2.54 \mathrm{~cm}, \mathrm{l} \mathrm{gal}=3.7854 \mathrm{~L}, \mathrm{PA}=$ polyamide, $\mathrm{PLA}=$ polylactic acid, $\mathrm{PU}=$ polyurethane, $\mathrm{TO}=$ tung oil . ${ }^{y}$ Cost was calculated based on 2012 wholesale prices of containers and estimated material costs for coating, when applicable.

${ }^{x}$ Rating $(5$ = best, $0=$ worst $)$ based on coating process and handling requirements.

"Not applicable. 


\section{Container performance and characteristics}

GREENHOUSE PRODUCTION TRIAL. Plants grown in paper- and coir-fiber containers coated with PA, PLA, or PU had dry weights similar to plants grown in petroleum-plastic containers (Table 3 ). The normalized means for dry weights of plants grown in PA-coated paper-fiber containers as well as PU-coated paper- and coirfiber containers were not different from the normalized mean for plants grown in petroleum-plastic containers (Table 3). Normalized dry weight was greatest for plants grown in PU-coated paper-fiber containers, and these containers, along with the petroleum-plastic containers and the PA-coated paper-fiber containers, produced the greatest dry weights of plants (Table 3). Of the five species produced, marigold was the only one for which growth of plants in PUcoated paper-fiber containers did not exceed growth of plants in uncoated paper-fiber containers, although dry weights were greater for marigold grown in PU-coated coir-fiber containers than for marigolds grown in uncoated coir-fiber containers. Across species, normalized dry weights of plants grown in coir- and wood-fiber containers coated with TO were less than those grown in uncoated containers (Table 3). Pepper, salvia, and tomato were more sensitive than marigold and petunia to the TO coating, and the negative effects of the TO coating were less pronounced with paper-fiber containers than with wood-fiber and coir-fiber containers. Regardless of the type of fiber material, plants grown in TO-coated containers received the lowest plant health ratings when compared with all other container types.

STRUCTURAL EVALUATIONS AND CONTAINER INTEGRITY. Coatings of PA, PLA, and PU increased strength of all types of containers relative to their uncoated counterparts (Table 4). TO-coated containers were not evaluated because of their poor performance in initial experiments and high cost. Resistance of coated paperfiber containers to vertical and horizontal compression was similar to, or greater than, that of petroleum-plastic containers (Table 4). Although tensile strength was greater for petroleumplastic containers than for any other uncoated or coated containers (Table 4), PLA coating improved tensile strength of fiber containers more than other biopolymer coatings. The PU coating, which was evaluated for seasonlong production of dogwood in no. 1 trade gallon paper-fiber containers, helped maintain container aesthetics and integrity (Fig. 1). The sidewalls of paper-fiber containers with a PU coating showed minimal signs of water soaking, whereas uncoated containers exhibited water soaking about half way up the container sidewall. Drainage holes showed little or no deterioration on containers coated with $\mathrm{PU}$, in contrast to those on uncoated containers (Fig. 1).

Degradation in soll. Of all container materials evaluated, uncoated paper-fiber and wood-fiber samples degraded the most during 6 months in soil, whereas uncoated coir-fiber and peat-fiber samples degraded less (Table 4). After $\mathbf{1 . 5}$ years in soil, the uncoated wood-fiber samples were completely degraded (indistinguishable from soil), whereas uncoated coir-fiber and peat-fiber samples had degraded $81 \%$ and $80 \%$, respectively. All fiber-container samples, both coated and uncoated, lost at least one-third of their original weights during 1.5 years in the soil. As expected, petroleum-plastic samples showed no degradation in soil after either 6 months or 1.5 years (Table 4). All biopolymer coatings decreased the degree of degradation of fiber-container samples relative to those of the same type that were uncoated, with the exception of coir-fiber samples evaluated after 6 months (Table 4). Reduction in degradation varied depending on the

Table 3. Plant dry weight, normalized dry weight, and health rating for 'Honeycomb' marigold, 'Autumn Bell' pepper, 'Madness ${ }^{\circledR}$ Red' petunia, 'St. John's Fire' salvia, and 'Rutgers' tomato grown in 4.5-inch $(11.43 \mathrm{~cm})$ petroleum-plastic containers and various biocontainers [coated and uncoated 4- to 5-inch (10.2 to $12.7 \mathrm{~cm})$ ] and harvested after 6 weeks of growth in a glass-glazed greenhouse. Plant dry weights for each species were normalized on a scale of 0 to 100 and used to calculate means across species (Pyle, 1999).

\begin{tabular}{|c|c|c|c|c|c|c|c|}
\hline \multirow[b]{2}{*}{ Container type $^{\mathrm{z}}$} & \multicolumn{5}{|c|}{ Plant dry wt $(g)^{y}$} & \multirow{2}{*}{$\begin{array}{l}\text { Normalized } \\
\text { dry wt }\end{array}$} & \multirow{2}{*}{$\begin{array}{c}\text { Plant health } \\
\text { rating }(0-5 \text { scale })\end{array}$} \\
\hline & Marigold & Pepper & Petunia & Salvia & Tomato & & \\
\hline Paper fiber-PU coat & $5.8 \mathrm{a}-\mathrm{c}^{\mathrm{x}}$ & $4.7 \mathrm{a}$ & $4.5 \mathrm{a}$ & $4.5 \mathrm{a}$ & $8.4 \mathrm{a}$ & $78.3 \mathrm{a}$ & $4.83 \mathrm{a}$ \\
\hline Paper fiber-PA coat & $6.3 \mathrm{a}$ & $4.3 \mathrm{ab}$ & $4.3 \mathrm{ab}$ & $3.8 \mathrm{~b}-\mathrm{d}$ & $7.8 \mathrm{a}$ & $73.0 \mathrm{a}$ & $4.83 \mathrm{a}$ \\
\hline Coir fiber-PU coat & $6.3 \mathrm{ab}$ & $4.2 \mathrm{a}-\mathrm{c}$ & $4.2 \mathrm{ab}$ & $3.4 \mathrm{c}-\mathrm{f}$ & $7.9 \mathrm{a}$ & $70.8 \mathrm{ab}$ & $4.89 \mathrm{a}$ \\
\hline Paper fiber-PLA coat & $5.5 \mathrm{a}-\mathrm{d}$ & $3.8 \mathrm{~b}-\mathrm{d}$ & $3.9 \mathrm{ab}$ & $4.1 \mathrm{ab}$ & $6.5 \mathrm{bc}$ & $64.6 \mathrm{bc}$ & $4.79 \mathrm{ab}$ \\
\hline Paper fiber-TO coat & $5.0 \mathrm{c}-\mathrm{f}$ & $3.6 \mathrm{c}-\mathrm{e}$ & $3.8 \mathrm{ab}$ & $2.8 \mathrm{fg}$ & $6.3 \mathrm{bc}$ & $55.8 \mathrm{~d}$ & $3.97 \mathrm{f}$ \\
\hline Coir fiber & $4.5 \mathrm{~d}-\mathrm{h}$ & $2.9 \mathrm{f}$ & $3.0 \mathrm{~cd}$ & $3.0 \mathrm{e}-\mathrm{g}$ & $5.7 \mathrm{c}-\mathrm{e}$ & $47.1 \mathrm{e}$ & $4.61 \mathrm{~cd}$ \\
\hline Wood fiber-PLA coat & $4.4 \mathrm{e}-\mathrm{h}$ & $3.1 \mathrm{ef}$ & $2.7 \mathrm{~d}$ & $3.2 \mathrm{~d}-\mathrm{f}$ & $4.8 \mathrm{~d}-\mathrm{f}$ & $44.5 \mathrm{ef}$ & $4.59 \mathrm{de}$ \\
\hline Wood fiber-PU coat & $3.9 \mathrm{~g}-\mathrm{i}$ & $2.6 \mathrm{f}$ & $2.5 \mathrm{~d}$ & $2.4 \mathrm{gh}$ & $5.3 \mathrm{c}-\mathrm{e}$ & $38.5 \mathrm{f}$ & $4.64 \mathrm{~b}-\mathrm{d}$ \\
\hline Peat fiber & $3.6 \mathrm{hi}$ & $2.5 \mathrm{f}$ & $2.6 \mathrm{~d}$ & $2.9 \mathrm{fg}$ & 4.7 ef & $37.7 \mathrm{f}$ & $4.43 \mathrm{e}$ \\
\hline
\end{tabular}

${ }^{\mathrm{z}} \mathrm{PA}=$ polyamide, $\mathrm{PLA}=$ polylactic acid, $\mathrm{PU}=$ polyurethane, $\mathrm{TO}=$ tung oil.

${ }^{\mathrm{y}} \mathrm{l} \mathrm{g}=0.0353 \mathrm{oz}$.

${ }^{x}$ Means within a column followed by the same letter are not significantly different according to Fisher's least significant difference test $(P \leq 0.05, n=5)$. 
Table 4. Vertical, horizontal, and tensile wet strength of new uncoated and coated fiber containers and percentage degradation of plastic and uncoated and coated fiber-container pieces held in soil for 6 mo. and 1.5 years.

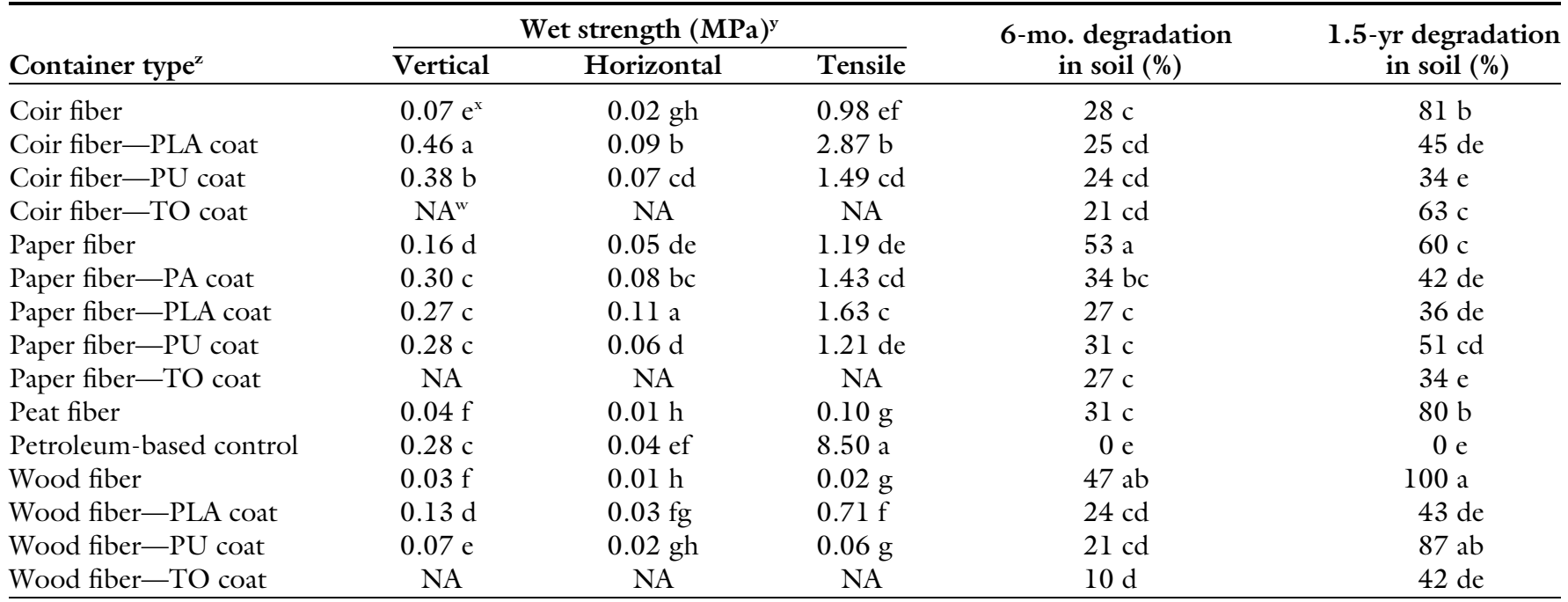

${ }^{2} \mathrm{PA}=$ polyamide, $\mathrm{PLA}=$ polylactic acid, $\mathrm{PU}=$ polyurethane, $\mathrm{TO}=$ tung oil.

${ }^{y} 1 \mathrm{MPa}=145.0377$ psi.

${ }^{\mathrm{x}}$ Means within a column followed by the same letter are not significantly different according to Fisher's least significant difference test $(P \leq 0.05, n=4$ for vertical and horizontal wet strengths, $n=8$ for tensile wet strength, $n=3$ for 6 -mo. and 1.5 -year soil degradation).

wot applicable.

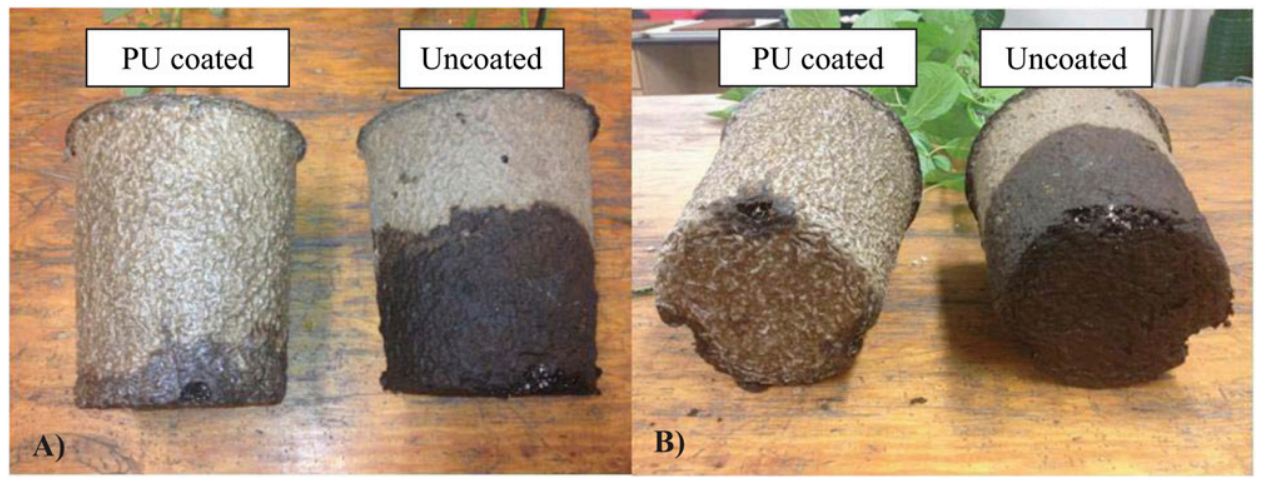

Fig. 1. Gallon-sized paper-fiber containers with and without a polyurethane (PU) coating. (A) Side view and (B) bottom view of containers that were used for $\mathbf{5}$ months in the production of redosier dogwood.

container material type and biopolymer coating. TO coatings minimized degradation of all fiber-container samples at 6 months, but did not minimize degradation of coir-fiber samples after 1.5 years. PLA and PU coatings caused similar reductions in degradation for all container material types, and PA reduced degradation of paper-fiber samples by $19 \%$ during the first 6 months (Table 4).

WATER-USE EFFICIENCY OF 4- TO 5-INCH CONTAINER TYPES. With the exception of the TO coating on coir fiber, coating fiber-based containers improved WUE (Figs. 2 and 3). Three of the coated-fiber containers facilitated WUE that did not differ significantly from that of the petroleumplastic containers. Paper-fiber containers coated with $\mathrm{PA}$ or PU and wood-fiber containers coated with PLA produced values of WUE that were similar to those from petroleum-plastic containers (Figs. 2 and 3 ). The TO coating on coir-fiber containers exhibited poor adhesion to the container, which was evident when oily residue began to leak from the container over time. The TO coating also caused chlorosis and necrosis on leaf margins, a condition especially prominent for plants cultured in the wood- and coir-fiber containers. The combination of poor coating adhesion and toxicity resulted in poor plant growth and health in TO-coated fiber containers (Table 3 ).

COMPARISON OF ONE AND TWO COATINGS OF PU ON PAPER-FIBER CONTAINERS. Both one and two coats of PU on 4.5-inch paper-fiber containers increased WUE to values similar to those from petroleum-plastic containers (Fig. 3). Although WUE of paper-fiber containers with one and two coats did not differ statistically from that of petroleum-plastic containers, we did find evidence that WUE of paper-fiber containers with two coats of PU was greater than that of containers with one coat (Fig. 3). On no. 1 trade gallon paper-fiber containers, two coats of PU increased WUE to values similar to those from petroleum-plastic containers. One coat of PU did not improve WUE to values similar to a petroleumplastic container of this size, but it did increase WUE relative to uncoated paper-fiber containers (Fig. 4). 


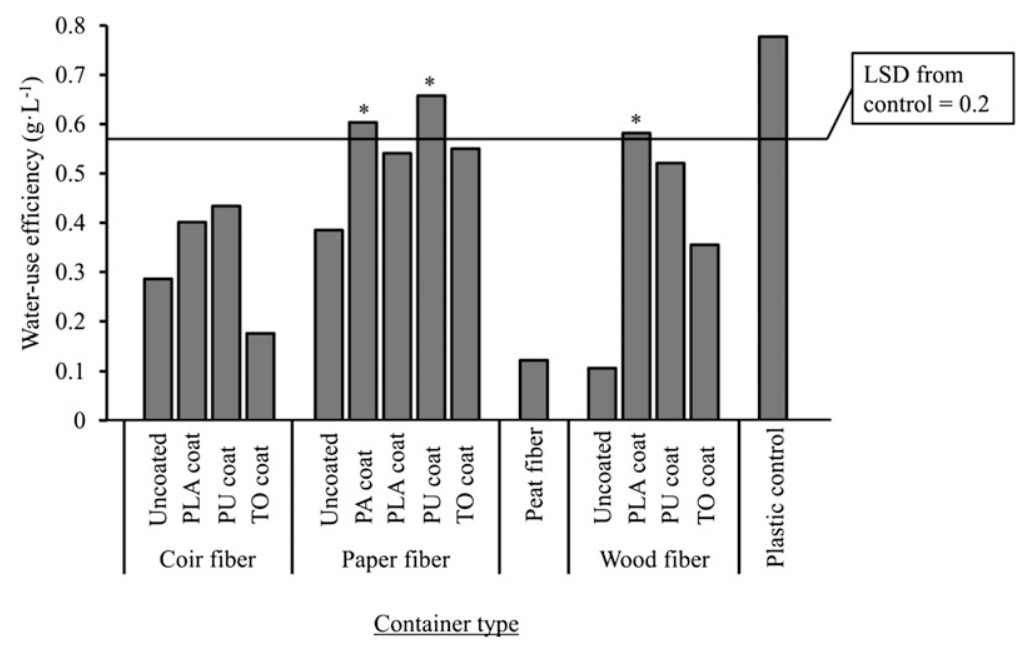

Fig. 2. Mean water-use efficiency of 4- to 5 -inch $(10.2$ to $12.7 \mathrm{~cm})$ containers growing 'St. John's Fire' salvia (PA = polyamide, $\mathrm{PLA}=$ polylactic acid, $\mathrm{PU}=$ polyurethane, TO = tung oil). Water-use efficiency is grams of plant dry weight divided by the liters of water required to produce the plant during 8 weeks of production under standard greenhouse conditions. Bars above least significant difference line are not significantly different from the plastic control according to Fisher's LSD test $(P \leq 0.05, n=5) ; 1 \mathrm{~g} \cdot \mathrm{L}^{-1}=0.1 \%$.

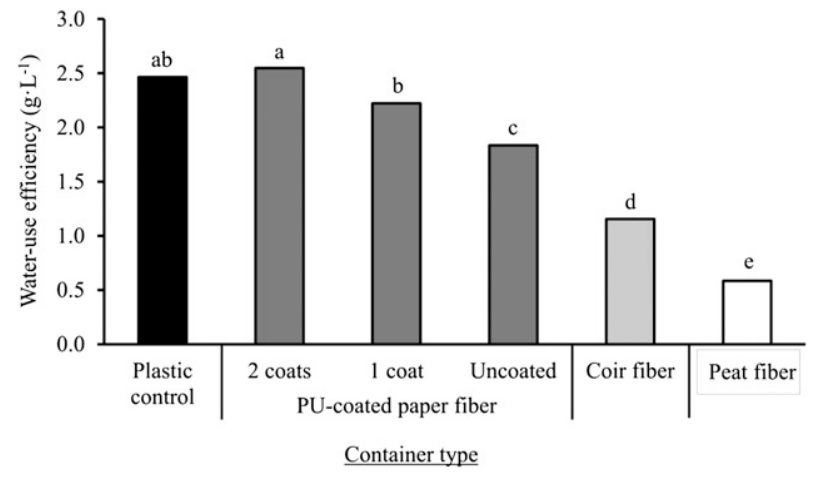

Fig. 3. Mean water-use efficiency of 4 - to 5 -inch $(10.2$ to $12.7 \mathrm{~cm})$ containers growing 'Rutgers' tomato ( $\mathrm{PU}=$ polyurethane). Water-use efficiency is grams of plant dry weight divided by the liters of water required to produce the plant during 6 weeks of production under standard greenhouse conditions. Bars with the same letter are not significantly different according to Fisher's least significant difference test $(P \leq 0.05, n=5) ; 1 \mathrm{~g} \cdot \mathrm{L}^{-1}=0.1 \%$.

Cumulative CONTAINer SCORES. PU-coated paper-fiber containers received the highest cumulative container score of the fiber containers evaluated. These containers scored nearly the same as petroleum-plastic containers across the 10 measurements (Table 5). The PU-coated coir-fiber container received the third highest score, and all four of the paper-fiber containers (regardless of coating treatment) scored in the top $50 \%$ of the containers evaluated. Uncoated paper-fiber containers scored better than all other uncoated containers, and uncoated wood-fiber containers scored the worst of all containers evaluated (Table 5). The largest coating-based increase in cumulative container score was achieved for coir-fiber containers with a PU coating, which improved the container score by 13.8 points (Table $5)$. Because of their high coating cost and relatively difficult coating process, paper-fiber containers coated with PA or PLA received cumulative scores lower than uncoated paperfiber containers, despite their improved performance and WUE (Tables 2-5). Petroleum-plastic containers received the highest cumulative score based on the 10 measurements, but received the lowest score for degradation in soil and received lower scores than some of the coated-fiber containers for measurements of container strength and plant growth and health (Tables 3-5).

\section{Discussion}

Growers will be reluctant to implement sustainable plant containers if the containers do not perform as well as the petroleum-plastic containers that are now the industry standard (Koeser et al., 2013a). However, most horticulturists likely would agree that there is no need for plant containers to last decades in the environment if their useful lifespan does not exceed several months to 2 or 3 years. Uncoated-fiber containers that are available commercially do not match the performance of petroleumplastic containers (Kuehny et al., 2011), but fiber containers coated with biopolymer may meet the performance demanded by current horticultural practices, while improving sustainability. Each type of biopolymer coating that we evaluated was unique with regard to cost, processability, physical properties, and characteristics. The strengths and weakness of each coating material and its performance with containers of different fibers must be considered when choosing sustainable alternatives that can meet the needs and preferences of growers.

With the exception of the TO coating, biopolymer coatings improved WUE, strength, and durability of fiber containers, but the overall potential of some of the coatings was reduced by low scores in other categories. Coatings of PA, PLA, and PU could facilitate a savings in water input during crop production, but the PU coating was the only biopolymer in our trials that provided this improvement at a reasonable cost (Table 2). PLA-coated containers were stronger than all other coatedfiber containers, but the difficulty and cost of coating with PLA makes it less appealing than PU for use as a coating on horticultural plant containers.

PU coatings provided a measurable increase in strength and durability at a relatively low cost, and PU was the easiest coating to apply. The improvements in WUE, strength, and durability of containers coated with PU, coupled with the low cost of materials and the ease of coating, indicate that $\mathrm{PU}$ is an effective and affordable biopolymer material for coating fiber containers. One of the 


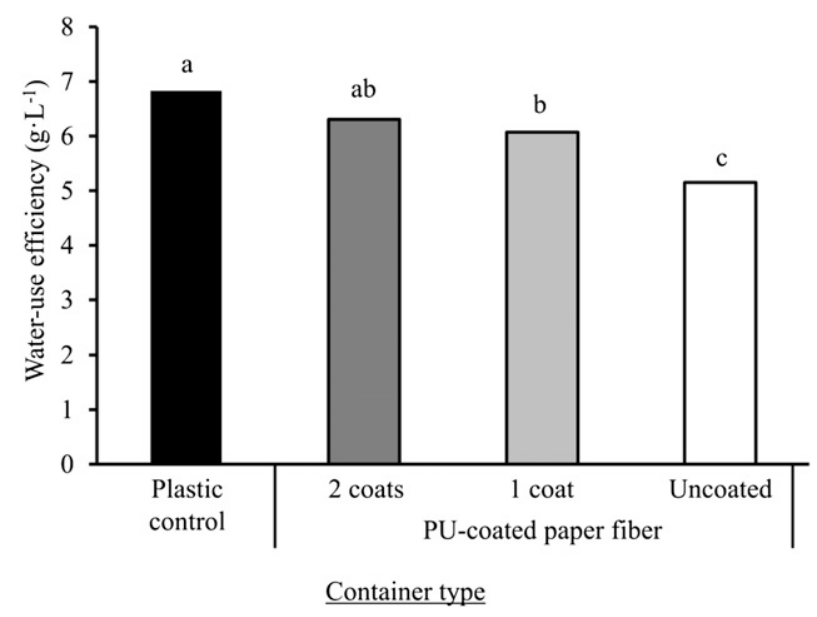

Fig. 4. Mean water-use efficiency for gallon containers growing 'Rutgers' tomato ( $P U=$ polyurethane). Water-use efficiency is grams of plant dry weight divided by the liters of water required to produce the plant during 7 weeks of production under standard greenhouse conditions. Bars with the same letter are not significantly different according to Fisher's least significant difference test $(P \leq 0.05, n=6) ; 1 \mathrm{~g} \cdot \mathrm{L}^{-1}=0.1 \%$.

Table 5. Cumulative container score of 4- to 5 -inch $(10.2$ to $12.7 \mathrm{~cm})$ containers based on 10 measures, including cost per container; ease of coating; degradation in soil; total wet strength; greenhouse scores for grower rating, plant health, plant size, and water-use efficiency; and landscape scores for plant health and plant shoot volume. Values for each parameter were standardized from 0 to 10 , for a maximum cumulative container score of 100 .

Container type ${ }^{\mathrm{z}}$

Cumulative container score

Petroleum-based control $(0-100 \text { scale })^{\mathrm{y}}$

Paper fiber-PU coat 87.4

Coir fiber-PU coat

86.4

Paper fiber

82.2

Paper fiber-PA coat

81.6

Paper fiber-PLA coat

74.4

Coir fiber-PLA coat

74.2

Wood fiber-PU coat

70.6

68.6

Coir fiber

68.4

Wood fiber-PLA coat

64.4

Peat fiber

64.2

Wood fiber

60.0

${ }^{\mathrm{z}} \mathrm{PA}=$ polyamide, $\mathrm{PLA}=$ polylactic acid, $\mathrm{PU}=$ polyurethane

y Cumulative container score on a scale from 0 to $100(0=$ worst, $100=$ best $)$.

most substantial outcomes of our research was our finding that PUcoated paper-fiber containers scored among the best in all 10 of our measured parameters. They were the least expensive of the coated-fiber containers, they had the easiest coating process, they degraded well in soil, they were strong and easy to handle, they grew plants well and with the highest WUE among fiber containers, and their use led to very good transplant establishment in the garden plot. These strong results earned PU-coated paper-fiber containers an overall score that was only slightly lower than that of petroleum-plastic containers (Table 5). For many growers, the strong improvement in sustainability using a container with performance similar to that of petroleum-plastic containers warrants consideration.

Commercially, the cost of containers is as important as performance. Growers are likely to resist adopting sustainable technology if it reduces profit. PU-coated paper-fiber containers that cost only a few cents more for materials than petroleum plastic for each 4.5-inch container and a few cents less than petroleum plastic for no. 1 trade gallon containers (Table 2 ) should be considered potential alternatives to petroleum-plastic containers. The increasing preference of consumers for plants produced by sustainable practices also is important. For example, Yue et al. (2011) found that consumers in Indiana, Michigan, Minnesota, and Texas indicated a willingness to pay more for plants grown in biodegradable, compostable, and recycled pots than plants grown in petroleum-plastic containers. Participants surveyed in Maine reported a willingness to spend $10 \%$ (ornamentals) to $15 \%$ (vegetables) more on plants that are grown sustainably (Hawkins et al., 2012). The opportunity to sell sustainably produced plants at a premium price is another incentive for switching to sustainable biocontainers, but the price that consumers are willing to pay depends on the biocontainer type (Yue et al., 2011). Responses of consumers to various types of commercially available biocontainers indicated that suitable price premiums ranged from $\$ 0.23$ to $\$ 0.58$ and that the carbon footprint of a specific biocontainer also influences the premium that consumers are willing to pay (Yue et al., 2011). Responses to containers labeled as carbon-negative suggested that a premium of $\$ 0.17$ was suitable, and responses to those labeled as carbon-intensive suggested a discount of about $\$ 0.43$ would be required (Yue et al., 2011). These reports suggest that a large number of consumers prefer sustainably produced plants and are willing to pay more for them. The minimal increase in cost associated with PU-coated fiber containers ( $\$ 0.03$ for coating materials) is well within a range that would allow growers and retailers to earn higher profits with sustainable containers that perform similarly to petroleum-plastic containers, but do so with a lower environmental impact.

Growers' acceptance and use of biocontainers has been limited by perceived risks associated with their use. Concerns about production risks and difficulty of implementation are the most significant factors limiting the adoption of sustainable practices in floriculture production (Hall et al., 2009). In a survey by Dennis et al. (2010), only $14.4 \%$ of green industry growers indicated that they use biodegradable plant containers, and only 
$4.8 \%$ use containers made from materials other than petroleum plastic. The low rates of biocontainer implementation in the green industry, coupled with increasing consumer demand for sustainable products, indicate an opportunity for growers to adopt biocontainers and create niche markets that are aimed at fulfilling consumer demand. The improvements in container performance achieved by coating fiber containers with biopolymers may help reduce the potential for risks and difficulties deterring the adoption of biocontainers.

Although a full life-cycle assessment is beyond our intended scope, it is important to highlight that paperfiber containers may have a lower environmental impact than other fiber containers because their base material is recycled paper. The recycled content of paper-fiber containers may be seen as an additional sustainable benefit because the bulk of these containers is both biorenewable and recycled. Results of life-cycle assessments of petroleum plastic and recycled paper (Zabaniotou and Kassidi, 2003), and of petroleum plastic and wood pulp composites (Hermansson, 2013), support the notion that biopolymer-coated fiber containers would be considerably more sustainable than petroleumplastic containers for single use.

We are not aware of a commercial source for "biopolymer-coated" fiber containers for horticultural crop production, but our results provide proof-of-concept for paper-fiber containers coated with bio-based PU. For growers and manufacturers who might be interested in characteristics other than those provided by PUcoated paper-fiber containers, our results provide practical information to help guide selection and development of other types of biopolymer-coated fiber containers that could match their needs.

\section{Literature cited}

Beeson, R.C. Jr., M.A. Arnold, B.B. Bilderback, S. Chandler, H.M. Gramling, J.D. Lea-Cox, J.R. Harris, P.J. Klinger, H.M. Mathers, J.M. Ruter, and T.H. Yeager. 2004. Strategic vision of container nursery irrigation in the next ten years. J. Environ. Hort. 22:113-115.

Dennis, J.H., R.G. Lopez, B.K. Behe, C.R. Hall, C. Yue, and B.L. Campbell. 2010. Sustainable production practices adopted by greenhouse and nursery plant growers. HortScience 45:1232-1237.

Evans, M.R. and D.L. Hensley. 2004. Plant growth in plastic, peat, and processed poultry feather fiber growing containers. HortScience 39:1012-1014.

Evans, M.R. and D. Karcher. 2004. Properties of plastic, peat, and processed poultry feather fiber growing containers. HortScience 39:1008-1011.

Evans, M.R., M. Taylor, and J. Kuehny. 2010. Physical properties of biocontainers for greenhouse crops production. HortTechnology 20:549-555.

Hall, T.J., J.H. Dennis, R.G. Lopez, and M.I. Marshall. 2009. Factors affecting growers' willingness to adopt sustainable floriculture practices. HortScience 44:1346-1351.

Hawkins, G., S.E. Burnett, and L.B. Stack. 2012. Survey of consumer interest in organic, sustainable, and local containergrown plants in Maine. Hort Technology 22:817-825.

Helgeson, M.S., W.R. Graves, D. Grewell, and G. Srinivasan. 2009. Degradation and nitrogen release of zein-based bioplastic containers. J. Environ. Hort 27:123-127.

Hermansson, F. 2013. Environmental evaluation of bio-composites using LCA. Chalmers University of Technology, Göteborg, Sweden, Master's Thesis.
Koeser, A., G. Kling, C. Miller, and D. Warnock. 2013a. Compatibility of biocontainers in commercial greenhouse crop production. HortTechnology 23: 149-156.

Koeser, A., S.T. Lovell, M. Evans, and J.R. Stewart. 2013b. Biocontainer water use in short-term greenhouse crop production. Hort Technology 23:215-219.

Kuehny, J.S., M. Taylor, and M.R. Evans. 2011. Greenhouse and landscape performance of bedding plants in biocontainers. HortTechnology 21:155-161.

Pyle, D. 1999. Data preparation for data mining. Morgan Kaufmann Publ., San Francisco, CA.

Schrader, J.A. 2013. Report on the annual consumption of plastics for specialty-crop containers in the United States. 12 Dec. 2013. <http://www.public. iastate.edu/ bioplastic/Supplementary/ AnnualPlastic.html>

Schrader, J.A., G. Srinivasan, D. Grewell, K.G. McCabe, and W.R. Graves. 2013. Fertilizer effects of soy-plastic containers during crop production and transplant establishment. HortScience 48:724-731.

U.S. Department of Agriculture. 2013. Floriculture crops 2012 summary. 12 Dec. 2013. <http://usda01.library.cornell.edu/ usda/current/FlorCrop/FlorCrop-04-252013.pdfs.

U.S. Environmental Protection Agency. 2013. Plastics. 12 Dec. 2013. <http:// www.epa.gov/wastes/conserve/materials/ plastics.htm>.

Yue, C., J.H. Dennis, B.K. Behe, C.R. Hall, B.L. Campbell, and R.G. Lopez. 2011. Investigating consumer preference for organic, local, or sustainable plants. HortScience 46:610-615.

Zabaniotou, A. and E. Kassidi. 2003. Life cycle assessment applied to egg packaging made from polystyrene and recycled paper. J. Clean. Prod. 11:549-559. 